\title{
Nature, creation and morality: The case of parasites
}

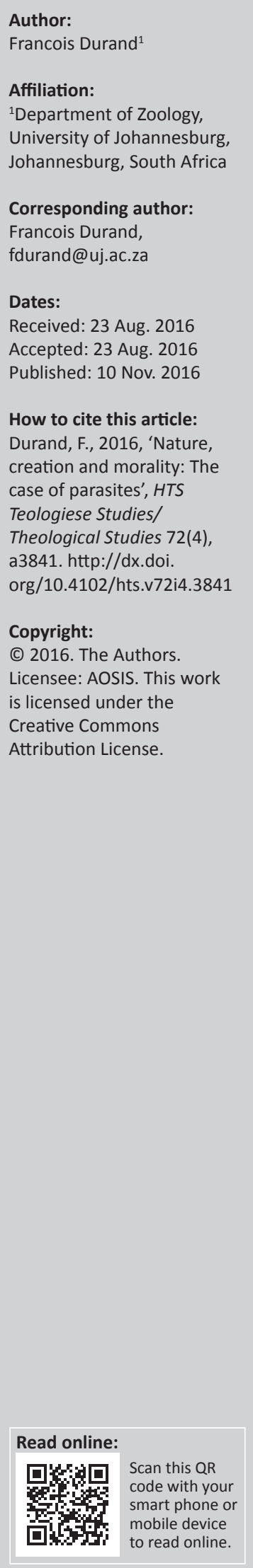

Nature is paramount to our existence. Humankind clearly realised the importance of nature since the beginning of our sapient abilities. Archaeological evidence shows how humans revered nature and how natural phenomena were mystified. This mystification of nature inspired animism and many associated religious rites, some of which are still part of our cultural existence. Some of the important results that stemmed from the mystification of nature is that it was seen as either good, being the handiwork of God or Gods, or that it started out as perfect but then became bad after the fall. Scientific research however show that there is no morality or hidden codes in nature, but that nature consists of random events, some which benefit humans, while others do not. Parasitology serves as a good example to show how extremely non-humane nature can be and how naïve and idealised our view of nature is. Not only did parasites exist on the planet since the beginning of life on earth and long before the existence of hominins, but the majority of all known animals are parasites. The latest research shows that parasites have a very important role in the ecology and that life as it exists would not have been possible without them. This implies that our romanticised ideas of ecology, biodiversity, the morality of nature and the purpose of life should be reviewed.

\section{Introduction}

Archaeological discoveries not only show how humans have tried to understand nature on the one hand but also show us how metaphysical meaning was given to natural phenomena on the other. Fertility, conception, birth, pair-bonding, death, germination of plants, drought, rain and solstice - to name a few natural phenomena - have been mystified in many cultures. With animism, metaphysical values were ascribed to these natural phenomena and later gods were assigned to them. Ritualised behaviour developed around natural phenomena and people believed that it was possible to understand the will of the gods by studying them. Natural phenomena were interpreted as good and bad and that it was proof of the greatness of the gods which blessed people by means of fertility, birth, children, crops and rain, or punished them with droughts, barrenness, failed crops, starvation, disease and death. Therefore, people believed that it was necessary to appease the gods through rituals associated with these phenomena. This is the reason for the existence of fertility rites, burial, marriage, baptism, harvest festivals, blessing rites and prayers for rain from prehistory to today. Religion would have been completely different if not for our struggle to come to terms with nature and our penchant to ascribe moral values to natural phenomena.

\section{The nature of nature}

Many religious writers, notably Creationists, insist that nature is not only the creation of God but also a perfect product reflecting the perfection and wisdom of God (Dembski \& Wells 2008; Wilson 2013). The assumption is that because God is omniscient and omnipotent and all-loving that everything in nature is good. Of course, there are predators and pests but those are the result of the fall of man. After the Second Coming, things will return to how they were before. The fall of man when there was no death and no suffering.

The concept that nature reflects the mind or will of God and even the spirit of God (Rahner 1966; Wilson 2013) must be questioned in the light of biological, ecological and medicinal reality.

\section{Parasites as example of the 'neutrality' of nature}

There are far more threats in nature than lions. For example, - every living organism is the host of at least one species of parasite, and many organisms, including humans, have far more than one. There are even parasites on parasites on parasites.

Certain frogs may harbour more than a dozen parasite species while at least 30 species of mites have been identified in the feathers of a certain parrot species. On the other hand, there are over 
200 species which commonly parasitise dogs. The majority of species are in fact parasites - humans included. Simply put: if an organism does not eat dead organic matter (which is what certain bacteria, saprophytic fungi and scavenging animals do), if it is not a predator which kills and consumes its prey and if it does not generate its own food by means of photosynthesis, then the chances are that it is a parasite. The definition of a parasite is something that feeds off another organism or its produce without killing it. Although some parasites live inside their hosts, others live on the surface of their hosts and yet others just feed off the first host and then move on to feed on another host. Herbivores such as stink bugs, antelope, monkeys and humans are examples of the last category.

Regardless of whether an animal such as a fruit fly sucks a small amount of sap from an apple, or when a fruit beetle eats a hole in it or a human eats the whole, they remain apple tree parasites. Humans are also cow, chicken, bee and pumpkin parasites. Insects constitute about half of all known species on earth and the majority feed off plants. Biologists have no idea of the exact number of parasite species on earth but they do agree that parasites constitute the majority of species on earth (Windsor 1998; Rocha et al. 2016). Parasites are found amongst the insects, crustaceans, flatworms, annelids, roundworms, vertebrates, plants, fungi and bacteria.

Parasites are not necessarily always detrimental to an organism's health. In most cases, organisms co-evolved over millions of years with parasites and can tolerate moderate numbers and diversity of parasites. It is gradually becoming clear how important parasites are on many levels of existence, including the individual, the population and the ecosystem level (Wood \& Johnson 2015). Parasites have an impact on the immune systems of their hosts and play an important role in natural selection. Parasites are an important factor for the maintenance of population dynamics which is one of the controlling mechanisms of the composition of ecological communities. This in turn modifies trophic interactions which has an impact on the whole food web from the rate of predation to the recycling and availability of nutrients (Rocha, Bergallo \& Bittencourt 2016).

The adaptations of parasites and their overwhelmingly important role in food webs indicate that they have been around for millions of years, long before humans existed. The fossil record of Ophiocordyceps for instance could be traced back to 48 million years ago (Hughes, Wappler \& Labandeira 2011). The evolutionary adaptations and feeding strategies of predators pale in comparison with the intricate adaptations and strategies of parasites. A few examples to prove this point are Ophiocordyceps, Dicrocoelium and Sacculina.

The spores of Ophiocordyceps unilateralis, also known as the Zombie fungus, attach to ants foraging in the forest. The spores enter the ant's body by dissolving its exoskeleton by means of enzymes and mechanical pressure. The spore transforms into a yeast-like cell and then starts to multiply as it spreads through the ant's body. The ant falls to the forest floor owing to convulsions which rack its body. The parasitised ant then climbs up the nearest plant and then locks its jaws onto a leaf vein with an abnormally strong force. The fungal parasite then immobilises the ant by destroying the connections in the muscle fibres in order to keep it in place. The ant dies as the parasite's hyphae spread through its tissues and sporangia burst through the ant's head to release spores which infect other ants (see Figure 1).

Snails often feed on fresh cow dung, some of which may contain thousands of tiny Dicrocoelium dendriticum eggs. The digestive enzymes and moisture inside the snail cause the eggs to hatch. The parasitic larvae migrate to the host's digestive glands where they transform into the tadpole-like flukes. The adolescent flukes then migrate to the respiratory chamber where they attach to the lining. The irritation caused by these flukes causes thick mucus to form which is ejected by the snail. These nutrient-rich blobs of fluke-containing mucus are then collected by ants which take them back to the colony. The flukes enter the ant's bodies when the mucus is consumed by the ants from where some migrate to the ant's nervous system. The parasitised ants do not return to their underground nest after working all day like their compatriots - they wander off in a daze obeying the commands of the flukes in their brain. The infected ant then crawls up a blade of grass to the tip and bites down hard where it remains like that through the night without moving or feeding until the next morning.

If the ant survives this, it will release the grass after it has heated up sufficiently the next day and then wander off to forage but when the sun sets, the mind-controlling flukes will force it to climb up a blade of grass and bite down onto it again. This behaviour will continue until the ant is swallowed by a grazing cow. Even then the ant will continue to cling to

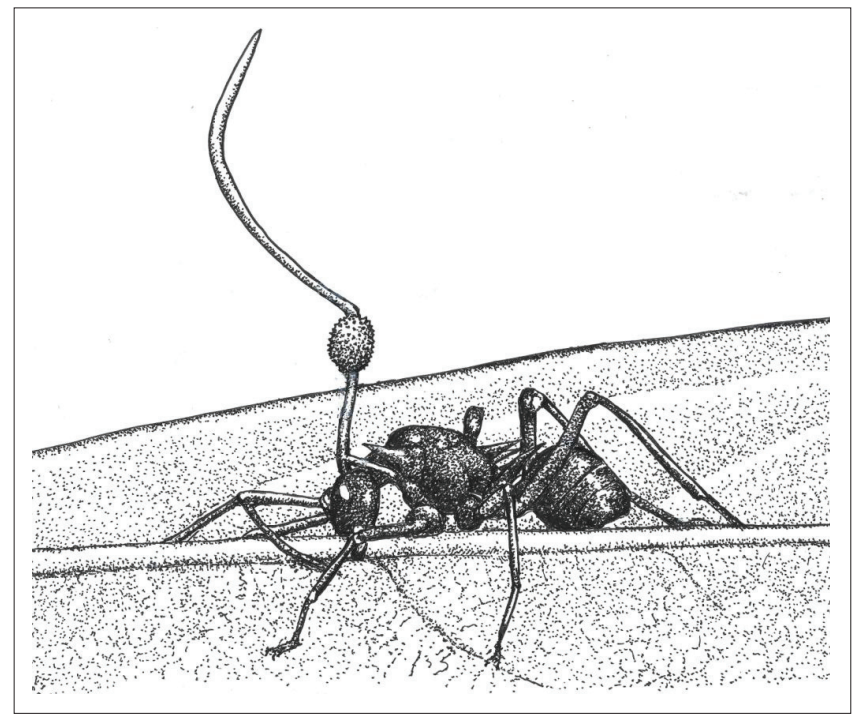

Source: Author's own work

FIGURE 1: The sporangium of the Zombie ant fungus Ophiocordyceps unilateralis growing from an ant's head. 
the grass as it is consumed by the cow. The flukes burst from the dying ant's abdomen as soon as they are inside the cow's digestive system. They swim with their tadpole-like tails through the cow's digestive system until they arrive at the bile duct where they settle down for the remainder of their lives. Here, they produce thousands of eggs which are carried from the bile duct into the cow's digestive system from which they are expelled together with the dung.

In the early stages of its life-cycle, Sacculina carcini occurs as a typical barnacle-type cypris larva as part of the plankton. The female Sacculina larva finds a crab and walks on it until it finds a joint in the exoskeleton where it attaches itself. It then moults into a form called a kentrogon, which injects its soft slug-like body into the crab while the cypris exoskeleton remains behind. The new soft-bodied slug, living inside the crab host, is called a vermigon. The vermigon starts to subdivide to form root-like tendrils throughout the crab's body which absorb nutrients from the crab's tissues (see Figure 2).

The female Sacculina matures as she invades the abdominal area of the crab to form an external egg sac, containing thousands of Sacculina eggs, and it protrudes through the crab's exoskeleton into the area where the crab's eggs should have been. When a female Sacculina invades a male crab, she disrupts his hormones so that it behaves like a female crab and then proceeds to castrate him. She also changes his internal and external body structure to resemble that of a female crab. She then proceeds to form her egg sac which the previously male crab now nurtures like a female crab would. The crab stops moulting, growing and mating when it is parasitised but continues to eat in order to serve the parasite by hosting and feeding it and nurturing and distributing its eggs.

The male Sacculina cypris larva searches for the female Sacculina's egg sac on the underside of the crab. He then enters the sac through a pinhole-sized hole by injecting the soft part of his body into it leaving the exoskeleton behind. He implants himself into her body permanently and starts fertilising thousands of eggs for the remainder of his life.

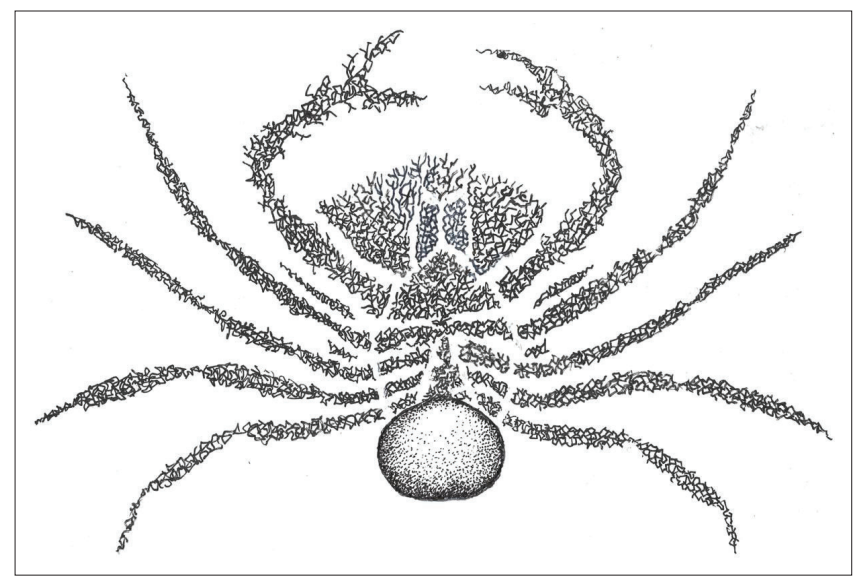

Source: Author's own work

FIGURE 2: Adult Sacculina in the body of a crab.
The female Sacculina normally hosts two of these males. When the Sacculina eggs are ready to be released the crab positions itself on a prominent spot and starts to bob while releasing pulses containing thousands of eggs which has only one purpose, namely to parasitise other crabs.

The majority of the 7 billion global human population and all other species are infected with parasites. Over a billion people, mostly children, are affected by parasitic diseases, causing about 14 million deaths per year. For example, between 300 and 500 million people contract malaria every year, leading to the death of about 2 million people annually, mostly children younger than age five. Diarrhoea caused by viruses, bacteria and protozoa is the second leading cause of death in children younger than age five. About 1.7 billion cases of diarrhoea lead to the death of three quarters of a million children younger than age five. People who die from diarrhoea in fact die from severe dehydration.

\section{Religion, nature and morality}

People who witnessed diseases such as the Black Death, which wiped out an estimated 75 million people, half of the population in Europe during the mid-14th Century, came to the conclusion that it was because of the wrath of God (Boccaccio 14th Century). A sect of religious zealots called the Flagellants tried to atone for the sins of humankind and to appease God by flagellating themselves in order to stop the plague. The Jews were blamed not only for invoking the ire of God but also the spread of the disease. It was believed that in order to appease God, communities had to be purged of heretics, which unfortunately included people of other religions, which resulted in the massacre of thousands of Jews in Europe during 1348-1349 (Porter 2014).

Darwin (1860) poignantly wrote to his friend Asa Grey after the slow and painful death of his beloved daughter Annie:

I had no intention to write atheistically. But I own that I cannot see as plainly as others do, and as I should wish to do, evidence of design and beneficence on all sides of us. There seems to me too much misery in the world. I cannot persuade myself that a beneficent and omnipotent God could have designedly created the Ichneumonidae with the express intention of their feeding within the living bodies of Caterpillars ... (p. 224)

Darwin's words read as if they are a scientific statement but they are in fact a testimony of his outlook on life and religion, and his disenchantment with God. He asks how God could have purposefully created the Ichneumonidae or parasitic wasps that can only survive by laying their eggs inside the live bodies of other species. The eggs will hatch and consume first the fat and then the muscles of the host over several days while keeping the host alive. The larvae of some parasitic wasp species bite holes in the sides of the host to respire. Finally, the parasitic wasp larvae burst through the body wall of their live host, now writhing in pain, to form pupae on its fresh carcass. Darwin could have used malaria, the Zombie fungus or Sacculina as examples. But more to the point, he could have referred to the millions of children, 
who like his own, died without a good reason, and in some cases died a horrible slow death. Around the world, about 21000 people, mostly children, die from starvation every day (see Figure 3).

\section{Moralising nature}

The tendency to ascribe morality to nature (as the expression of God's will) and the assumption that natural phenomena must be good or evil are probably as old as human consciousness. People tend to look at nature in a romantic and often naive way enjoying sunsets, birdsongs and flowers but do not look closely enough to see that each organism is teeming with others already feeding off it. Human empathy is evoked when we see a predator ripping its prey to shreds and starts devouring it, often while it is still alive. Similarly, humans respond with revulsion and outrage at diseases and parasites and the resultant suffering.

These emotions are however unique to humans and may be present in an incipient form in animals of higher intelligence such as the great apes and dolphins. The need to see natural phenomena as good or bad reflects an emotional need in humans which is not reflected in nature. Attempts to impose human morality systems on nature will obviously be frustrating, and people will constantly be disillusioned by the failure of nature to harmonise with their beliefs.

Evolutionists and palaeontologists not only enabled us better to understand nature and the processes governing it but also demonstrated that we are part of nature. Unfortunately, that did not turn us into more objective thinkers because we are still guilty of anthropomorphising, especially mammals, which is the reason why it is easier for us to empathise with mammals than with other organisms. Proof for this is the fact that we keep mammals as pets more often than other organisms, the majority of animals at zoos are mammals and the main focus of nature conservation is on mammal biodiversity. The fact that there are over 1200000 known species in comparison with only approximately 5500 mammal species illustrates our bias

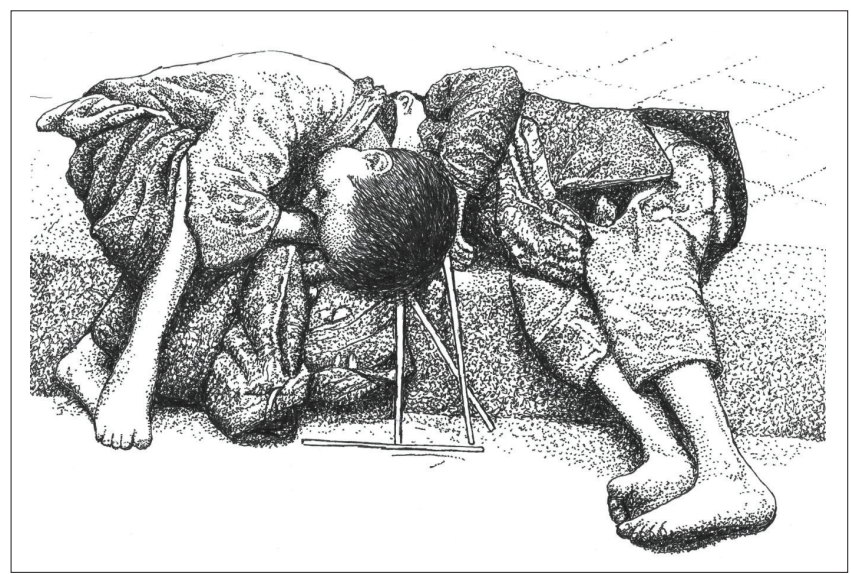

Source: Author's own work based on photo in LIFE 1946

FIGURE 3: Two small children dying together during the famine of 1958-1962 in China when approximately 45 million people died of starvation. towards mammals which constitute only a very small part of biodiversity.

Ironically, there is a need for human emotional involvement with nature. It is this emotion which inspires people to try to save the whale, the rhinoceros or the cheetah. Notably, the majority of these attempts focus on mammals and not on reptiles or invertebrates. In some cases, invertebrates, for example, bees on which approximately 250000 plant species' existence depends may play a more important ecological role than the cheetah or rhinoceros. On the other hand, each of these animal species may be the home of tens, if not hundreds, of species of parasites who in some cases may be species specific and become extinct if their host disappears.

Saving the whale will also save whale lice and a multitude of other organisms that depend on it (Koh et al. 2004; Rocha et al. 2016). One could argue that in order to save biodiversity, one should try and save all species and not the one that you are culturally programmed to revere more than others. Clearly, every species has a role in the ecology, and in order to save biodiversity one should attempt to save all species and not only those that are attractive (Gómez \& Nichols 2013; Rocha et al. 2016). The emotional connection between humans and nature, although flawed in some respects, and often not very objective, could be the last chance to conserve nature in the face of the growing ecological catastrophe.

Life on earth is sustained primarily by photosynthesis - the notable exceptions are the chemosynthetic food web along the mid-oceanic vents and geophagous bacteria that consume water and rock alone. The next trophic level in the ecology consists of organisms that feed on these primary producers and on each other. In the process, organic molecules are passed from one organism to the other, which will continue until the sun burns out. The only way the biological component of nature can exist is in one organism feeding off the other and in this way maintaining order in nature.

The fact that the majority of known species are parasites and therefore play a crucial role in the ecology should be taken cognisance of in any attempt to understand nature and the role of humankind in nature. Biodiversity in fact is dominated by parasitic species which play an intricate and essential part in this flow of nutrients through the food web. One can conclude that the only way in which the majority of the known species can exist is by feeding off others, often in the most horrific way with complete indifference to the resultant suffering. In this Malthusian nightmare, a surplus of organisms, humans included, exist in order to sustain others.

Nature can be seen as organic molecules that are dispassionately passed on from one organism to another, sometimes when the first is dead, but often when it is alive, in a great flow of energy in an interconnected web of life. To ascribe morality to nature is wrong because nature is neither good nor bad - it is amoral. 


\section{Acknowledgements}

\section{Competing interests}

The author declares that he has no financial or personal relationships which may have inappropriately influenced him in writing this article.

\section{References}

Boccaccio, G., 1972, The Decameron (14th century), transl. G.H. McWilliam (ed.), Penguin Books, London.

Darwin, C., 1859, On the origin of species by means of natural selection, or the preservation of favoured races in the struggle for life, John Murray, London.

Darwin, C., 1993 (1860), The Correspondence of Charles Darwin, Volume 8, edited by F. Burkhardt et al., p. 224, Cambridge University Press, Cambridge.

Dembski, W. \& Wells, J., 2008, The design of life: Discovering signs of intelligence in biological Systems, Foundation for Thought and Ethics, Dallas. TX.

Gómez, A. \& Nichols, E., 2013, 'Neglected wild life: Parasitic biodiversity as a conservation target', International Journal of Parasitology, Parasites and Wildlife 2, 222-227. http://dx.doi.org/10.1016/j.ijppaw.2013.07.002
Hughes, D.P., Wappler, T. \& Labandeira, C.C., 2011, 'Ancient death-grip leaf scars reveal ant fungal parasitism', Biology Letters 7(1), 67-70. http://dx.doi. org/10.1098/rsbl.2010.0521

Koh, L.P., Dunn, R.R., Sodhi, N.S., Colwell, R.K., Proctor, H.C. \& Smith, V., 2004, 'Species coextinctions and the biodiversity Crisis', Science 305, 1632-1634. http://dx.doi. org/10.1126/science.1101101

Porter, C.M., 2014, 'The Black Death and the persecution of the Jews', Saber and Scroll $3(1), 54-65$.

Rahner, K., 1966, 'Christology within an evolutionary view', Theological Investigations 5, 157-192.

Rocha, C.F.D., Bergallo, H.G. \& Bittencourt, E.B., 2016, 'More than just invisible inhabitants: Parasites are important but neglected components of the biodiversity', Zoologia 33(3), e20150198, viewed from http://www.scielo.br/ pdf/zool/v33n3/1984-4689-zool-33-03-e20150198.pdf (Viewed: 10 August 2016).

Wilson, J.R., 2013, God's good world: Reclaiming the Doctrine of Creation, Baker Publishing, Grand Rapids. MI.

Windsor, D.A., 1998, 'Most of species on earth are parasites', International Journal for Parasitology 28, 1939-1941. http://dx.doi.org/10.1016/S00207519(98)00153-2

Wood, C.L. \& Johnson, P.T.J., 2015, 'A world without parasites: Exploring the hidden ecology of infection', Frontiers in Ecology and the Environment 13, 425-434. http://dx.doi.org/10.1890/140368 